\title{
An Evaluation of Book Selection in a University Library by Loan Record Analysis
}

\author{
Mitsuro Kitajima, Kensuke Baba, and Toshiro Minami
}

\begin{abstract}
Book selection is an important operation in a library and should be conducted on the basis of reasonable data. This paper evaluates the process of book selection in a university library by analyzing the loan records. The authors classified the books in the library according to Nippon Decimal Classification (NDC), and investigated the turnover rate for each category. The results show that the book selection process in the library was appropriate in terms of the turnover rate although the process was not conducted with considering the turnover rate. Additionally, the authors considered the rate of the books that bought by researchers in the university and accessioned to the library. The results indicate some viewpoints for selecting books in university libraries.
\end{abstract}

Index Terms-Data mining, library, book selection, loan record.

\section{INTRODUCTION}

Book selection is one of the important operations in a library. To make good use of public property, the way of book selection should be evaluated and improved according to the result of the evaluation. In some Japanese university libraries, however, a part of the process depends on the static guide independently set in each library or the individual discretions of a staff of the library. To meet the constantly changing demands of library patrons, book selection should be operated by a dynamic way according to objective statistics.

There are two possible ways to evaluate the process of book selection, that is, evaluating the collection in themselves and analyzing use of the collection [1]. An analysis on use of books in a library had been conducted at latest 1961 [2]. Evans [3] investigated the numbers of loans for books classified by the person who had selected the book, academic staff, library staff, and book jobbers, in some academic libraries. Pritchard [4] also investigated the frequencies of loans for books selected on the basis of four criteria, new editions of already held books, requests on interlibrary loan, recommendations by library staff, and recommendations by academic staff. As for Japanese university libraries, Matsui and Isono [5] investigated the turnover rate of books in the library of Nara University, and found the typical change over the years (obsolescence) on the frequency of loans. The turnover rate is defined for a set of books to be the number of loans for a book. Koizumi [6] also

Manuscript received May 5, 2014; revised July 25, 2014

Mitsuro Kitajima and Kensuke Baba are with the Library of Kyushu University, 10-1, Hakozaki 6, Higashi-ku, Fukuoka, 812-8581, Japan (e-mail: kitajima.mitsuro.023@m.kyushu-u.ac.jp, k.baba.060@m.kyushu-u.ac.jp).

Toshiro Minami is with Kyushu Institute of Information Sciences, 3-1, Saifu 6, Dazaifu, Fukuoka, 818-0117, Japan (e-mail: minami@kiis.ac.jp). investigated the turnover rate of books in Keio University Library, and clarified the difference between book selections by librarians and faculties in the university. In our research, we considered the turnover rate for categorized books to find detailed tendencies in loan records.

The aim of our study is to find useful information for book selection in a library from its loan records. An idea of a "good" book selection is that the selected book is well borrowed by patrons, that is, the turnover rate of the book is high. Additionally, from the viewpoint of collections for academic researches, the number of books and the turnover rate are better to be balanced for each research area. Computing the turnover rates for each book is technically easy, but it has the following practical difficulties:

- Analyzing loan records in a library is often considered in connection with personal information or privacy matters,

- The results of loan record analyses cannot be applied straightforwardly to selection of new books.

The first difficulty seems to be remarkable especially in Japan because of historical reasons. The reason of the second difficulty is that book selection usually selects books that have not been already housed in the library. To avoid the difficulties, we classified books into some categories and identified the plural books in each category.

In this paper, we evaluated the book selections in Kyushu University Library. In the library, the process of book selection is mainly conducted on the basis of

- Requests from the faculties in the university (include designs in syllabuses),

- Requests from patrons of the library, or

- Selections by a staff of the library.

Additionally, some books are bought by researchers from their funds, and such books are accessioned formally to the library, but physically to their laboratories.

Currently, the loan records are not considered for the selections. We collected the book accession records from April 2000 to March 2013 and the book loan records from April 2012 to March 2013. We classified the books according to Nippon Decimal Classification (NDC), and investigated the relation between the rate of book accessions and the turnover rate for the books categorized into natural sciences. This investigation was also conducted for the book accession records from April 2012 to March 2013 to evaluate book selections in a short term. Additionally, we evaluated the book selections based on direct requests from researchers in the university in terms of the turnover rate. This evaluation was also conducted for books in social sciences, and the results showed a clear difference of the tendencies between the research areas.

Our study suggests some viewpoints for improving book selection in university libraries rather than proposing the 
absolute criterion.

The rest of this paper is organized as follows. Section II describes the methods for evaluating book selection and formalizes some metrics for the evaluation. Section III reports the results of the evaluation. Section IV shows considerations about findings at the evaluation and improvements of book selection according to the results.

\section{METHODS}

The book accession and loan records were collected at Kyushu University Library. We investigated the numbers of book accessions and loans for each category in NDC.

\section{A. Collected Data}

We collected the data of

- The books housed in the library as of March 2000,

- The books accessioned to the library from April 2000 to March 2013, and

- The books borrowed from the library from April 2012 to March 2013.

In the collected data, any book has the following two attributes:

- The NDC number and

- The place housing the book.

NDC is substantially the standard classification method in Japanese libraries and represented as 3-digit numbers. We considered the books classified into the categories from 400 to 499 in NDC. The categories 400-499 hierarchically correspond to research areas in natural sciences, for example, $4 * *$ is "Natural sciences", $41 *$ is "Mathematics", and 411 is "Algebra".

In the library, some book accessions are requested directly by researchers in the university, and the books are housed physically in the laboratories or offices of the researchers (formally, in the library for any book). Therefore, the value of the second attribute is "the library" or "a laboratory in the university". The book accession and loan records were collected at Kyushu University Library. We investigated the numbers of book accessions and loans for each category in NDC.

\section{B. Data Analysis}

First, we classified the books into the 100 categories in NDC. Then, we investigated the relation between the number of book accessions and the number of book loans for the classified books. To clarify the tendency of the relation in a short term, we additionally considered about the book accessions from April 2012 to March 2013.

Since the numbers of books in the categories were not equal, we considered the normalized values for the numbers of accessions and loans. Let $s_{t}$ be the number of books housed in a library at a time $t$. Let $a_{t, t^{\prime}}$ and $l_{t, t^{\prime}}$ be the numbers of the books accessioned to the library and the books borrowed from the library for the period from $t$ to $t^{\prime}$, respectively. Then, the accession rate and the turnover rate of the books in the library for the period from $t$ to $t^{\prime}$ are defined to be $a_{t, t} / s_{t^{\prime}}$ and $l_{t, t} / s_{t^{\prime}}$, respectively. Clearly, we can consider the two rates for any non-empty subset of the books. Then, the target of our investigation is the relation between the accession rate and the turnover rate, and the accession rate is considered for the 13 years and the 1 year.

$\mathrm{Next}$, we investigated the relation between the number of book loans and the number of books housed in laboratories. This investigation was conducted also for books in the categories 300-399 which correspond to social sciences. The lab-housing rate for a set of books is defined to be $r / s$, where $r$ is the number of the books housed in a laboratory (that is, the second attribute is "a laboratory") and $s$ is the cardinality of the set. We investigated the relation between the lab-housing rate for the books housed in the library at March 2013 and the turnover rate from April 2012 to March 2013 for books in the categories 400-499 and 300-399.

\section{RESUlts}

The numbers of

- The books housed in the library at March 2013,

- The book loans from April 2012 to March 2013,

- The book accessions from April 2000 to March 2013,

- The book accessions from April 2012 to March 2013, and

- The books housed in laboratories at March 2013

in the categories 400-499 were

- 114,699,

- 15,270 ,

- 9,043,

- 318 , and

- 33,224,

respectively. Note that the first number includes the last number. The number of the books "purely" housed in the library (that is, the books except for those housed in laboratories) is 81,475 . Fig. 1 shows the distribution of the numbers of books in the 100 categories. In the horizontal axis, the categories are sorted by the number of books. The largest and the smallest numbers were 6,933 and 17 , respectively.

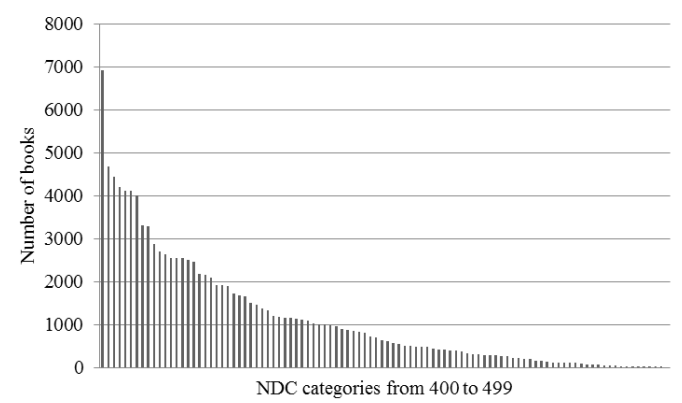

Fig. 1. The distribution of the numbers of books classified by NDC 400499

Fig. 2 shows the relation between the accession rate and the turnover rate for the books housed in the library. The left graph is for the accession rate from April 2000 to March 2013 and the right one is for that from April 2012 to March 2013. Note that the ratio of the scale of the horizontal axis in left to that in right is $13: 1$. Some remarkable points are labeled by the NDC numbers. The correlation coefficients between the two rates were 0.25 and 0.14 , respectively.

Fig. 3 shows the relation between the lab-housing rate at March 2013 and the turnover rate from April 2012 to March 2013 for the books in the library. The left graph is for the books categorized in NDC 400-499 (natural sciences), and the right one is for the books in 300-399 (social sciences). As 
for the categories 300-399, the numbers of

- The books housed in the library at March 2013,

- The book loans from April 2012 to March 2013, and

- The books housed in laboratories at March 2013

were

- 96,863 ,

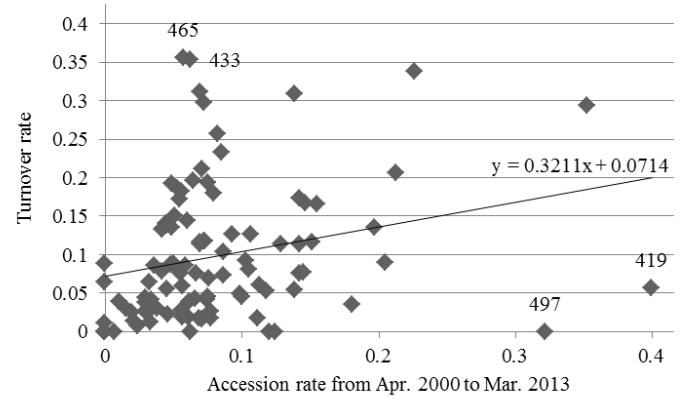

- 19,192 , and

- 26,094,

respectively. Some remarkable points are labeled by the NDC numbers. The correlation coefficient between the two rates was 0.17 in the natural sciences and -0.37 in the social sciences.

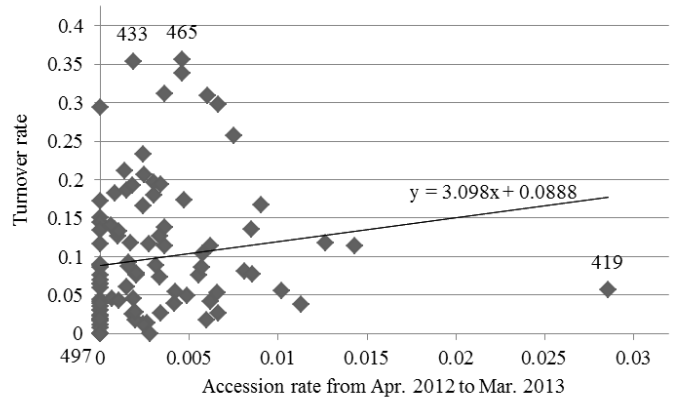

Fig. 2. The relation between the accession rate from April 2000 to March 2013 and the turnover rate (left) and the relation between the accession rate from April 2012 to March 2013 and the turnover rate (right), where the labeled points are "Mathematics of Nippon and China" (419), "Analytical chemistry" (433), "Microbes. Microbiology" (465), and "Dentistry" (497).
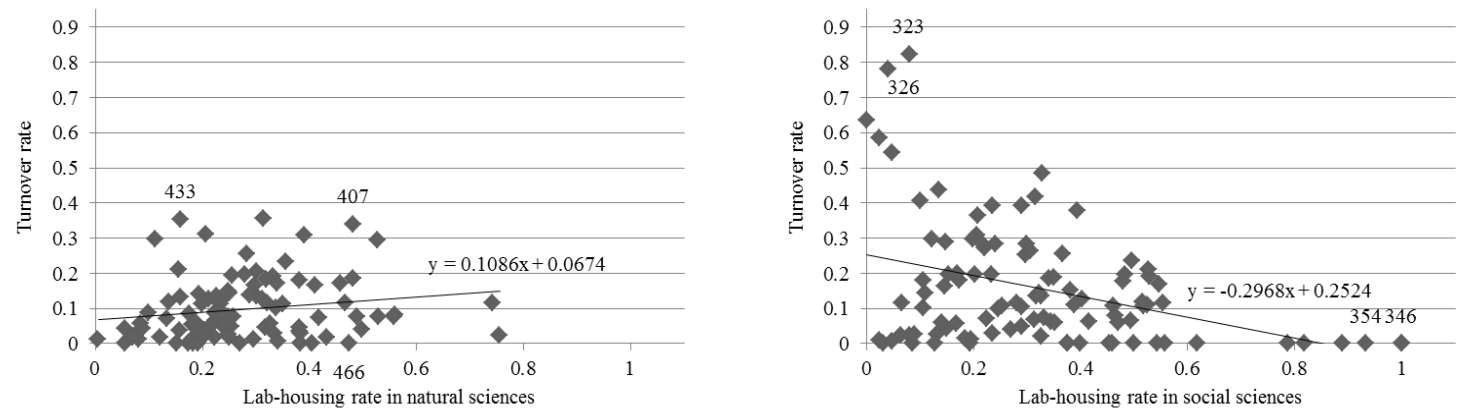

Fig. 3. The relation between the lab-housing rate and the turnover rate for books in natural sciences (left) and social sciences (right), where the labeled points are "Study and teaching" (407), "Analytical chemistry" (433), no title in "Biology" (466), "Constitutional law" (323), "Criminal law" (326), no title in "Public finance" (346), and "Africa" in "Statistics" (354)

\section{DISCUSSION}

\section{A. Major Conclusion}

By the left graph in Fig. 2, we found that there was a moderate correlation between the accession rate and the turnover rate. Therefore, we can conclude that the library was conducting mostly appropriate book selections in the sense of the turnover rate. However, the book selections in the library were not being conducted on the basis of the turnover rate as a policy of the library. Actually, in the right graph, the correlation of the turnover rate with the accession rate of the latest one year was positive but weaker than that of the 13 years.

Fig. 3 shows that the lab-housing rate had a positive correlation with the turnover rate for books in natural sciences and a negative correlation for books in social sciences. By the left graph, we can see that book selections based on requests from researchers were appropriate in the sense of the turnover rate for books in natural sciences. On the other hand, for books in social sciences, we can expect that library patrons were using books in the library and the laboratories for different purposes.

\section{B. Key Findings}

In the analysis on the relation between the accession rate and the turnover rate, the remarkable points "Analytical chemistry" (433) and "Microbes. Microbiology" (465) had the high turnover rates in spite of the low accession rates, which means that the books in the categories were borrowed frequently but similar books were not accessioned to the library. From this viewpoint, we can suggest that the library would select books in the categories for future book accession.

The other labeled points "Mathematics of Nippon and China" (419) and "Dentistry" (497) had the low turnover rates and the high accession rates. We expect that some books in the category "Mathematics of Nippon and China" were used for research rather than learning, and moreover, the research area has a property of a kind of social sciences, that is, we need to collect related literature widely. As for "Dentistry" (497), the accession rate in the latest year became 0 . Therefore, we can regard that the book selection in the library reflected the circumstance of use of patrons as the result, although the process was not considering the loan records.

For the relation between the lab-housing rate and the turnover rate, Fig. 3 shows a clear difference between natural sciences and social sciences. As we mentioned about "Mathematics of Nippon and China", some books in social sciences are collected as literature for academic researches. Therefore, we have the following hypotheses: 
- Some books housed in laboratories in social sciences were highly specialized,

- Some books in social sciences were borrowed also by non-specialists.

One of the categories with a high lab-housing rate and a low turnover rate in the right graph was "Africa" (354) in Statistics which is indeed a highly specialized research area in Japan. The two categories with a low lab-housing rate and a high turnover rate were included in "Law" $(32 *)$.

The categories 466 in the left graph and 346 in the right graph have no title, that is, those are not used. Therefore we consider that there were some mistakes of labeling at the library.

The books housed in the laboratories are included in the scope of a search at the on-line catalog system in the library, but do not exist in the library. The books in laboratories are mainly used by the people in the laboratories, and hence the number of loans from the library is few. Therefore, we also considered the proper turnover rate, that is, the turnover rate for books purely housed in the library.

Fig. 4 shows the relation between the lab-housing rate and the proper turnover rate for books in natural sciences. The correlation coefficient between the two rates was 0.40 . In the graph, "Study and teaching" (407) pointed a high turnover rate, which means that the turnover rate of the books in 407 was virtually low because of the high lab-housing rate.

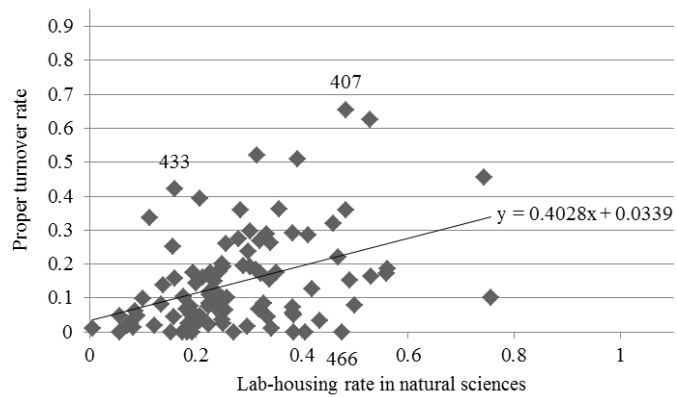

Fig. 4. The relation between the lab-housing rate and the turnover rate for books in natural sciences housed purely in the library.

\section{Future Directions}

In this subsection, we discuss about improvements of book selection in the library on the basis of the results of our evaluation. First of all, we consider selecting books that are expected to have high turnover rates as themselves. For this goal, researchers' selections in natural sciences are expected to lead high turnover rates. Additionally, we consider balancing the turnover rate for the categories. For these goals, we suggest the following policies:

- Selecting books with a low accession rate and a high turnover rate,

- Selection books with a high lab-housing rate and a high turnover rate.

For example, from these viewpoints, we suggest the library would select books in the categories "Analytical chemistry" (433), "Microbes. Microbiology" (465), "Constitutional law" (323), and "Criminal law" (326). Additionally, we also recommend books in "Study and teaching" (407) according to the result with the proper turnover rate.

\section{CONCLUSION}

We evaluated book selections in Kyushu University Library in terms of the turnover rate of the selected books. The book selections were appropriate in the sense of the turnover rate, although the selections were not decided by considering the turnover rate of similar books straightforwardly. Additionally, we found that book selections based on direct requests from researchers may lead a good turnover rate for books in natural sciences. As the result, we suggested the two viewpoints, the relation between the turnover rate and the accession rate and the relation between the turnover rate and the lab-housing rate, for considering book selection in university libraries.

\section{ACKNOWLEDGMENT}

This work was supported in part by Kyushu University Interdisciplinary Programs in Education and Projects in Research Development (P\&P) from 2013 to 2014.

\section{REFERENCES}

[1] F. W. Lancaster, If You Want To Evaluate Your Library, University of Illinois, 1988.

[2] H. H. Fussler and J. L. Simon, Patterns In The Use of Books In Large Research Libraries, University of Chicago Library, 1961.

[3] G. E. Evans, "Book selection and book collection usage in academic libraries," The Library Quarterly, vol. 40, no. 3, pp. 297-308, 1970.

[4] S. J. Pritchard, "Purchase and use of monographs originally requested on interlibrary loan in a medical school library," Library Acquisitions: Practice \& Theory, vol. 4, no. 2, pp. 135-139, 1980.

[5] A. Matsui and H. Isono, "An analytical survey of the loan transaction records using "turnover rates" and "circulation rates" - on some characteristics of the library material usage in Nara University - (in Japanese)," Memoirs of the Nara University, vol. 34, pp. 177-190, 2006.

[6] M. Koizumi, "Book selection by librarians and faculty through collection evaluation methods: A case study of Keio University Library in Japan (in Japanese)," Library and Information Science, vol. 63, pp. 41-59, 2010.

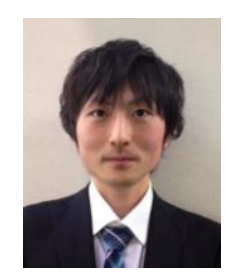

Mitsuro Kitajima was born in Japan in 1988. He received his BS degree from Kyushu University in 2011.

From 2011 to 2014 he was a librarian of Kyushu University. Currently, he is a staff of Information System Section of Kyushu University. His Research interests include data mining, library and information science.

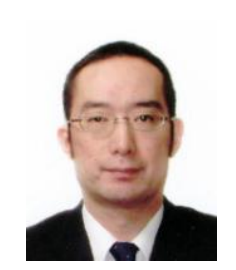

Kensuke Baba was born in Japan in 1973. He received his BS, MS, and D.Sc. degrees from Kyushu University in 1996, 1998, and 2002, respectively.

From 2002 to 2003 he was a research fellow and from 2003 to 2009 he was an assistant professor in Faculty of Information Science and Electrical Engineering in Kyushu University. Currently, he is an associate professor in the library of Kyushu University. His research interests include data mining, pattern recognition, and digital library. Dr. Baba is a member of IEEE and IPSJ.

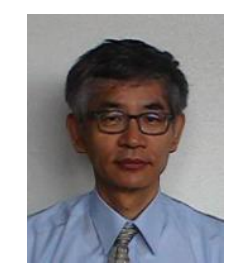

Toshiro Minami was born in Japan. He received his BS degree from Kyushu Institute of Technology in 1973, and MS and D.Sc. degrees from Kyushu University in 1975, and 1999, respectively.

He was a researcher of Fujitsu Limited and Fujitsu Laboratories Limited from 1984 to 1999, a research fellow of Australian National University from 1992 to 1993, an associate professor of Kyushu University Library from 1999 to 2001. He has been a professor of Kyushu Institute of Information Sciences since 2001. His research interests include multi-agent system, data mining and library informatics. 